\title{
Defect level and particle size effects on the hydrolysis of chemical warfare agent simulant by Ui0-66
}

Bradley Gibbons, Eamon C. Bartlett, Meng Cai, Xiaozhou Yang, Eric M. Johnson, Amanda J. Morris*

Department of Chemistry, Virginia Tech, Blacksburg, VA, 24061, USA 
Table of Contents

\begin{tabular}{|l|l|l|}
\hline Section & Content & Page \\
\hline 1 & Modulator Screening of UiO-66 & 2 \\
\hline 2 & PXRD & $3-4$ \\
\hline 3 & Discussion on TGA for determining defects in MOFs & $5-8$ \\
\hline 4 & TGA on defected UiO-66 & $9-12$ \\
\hline 5 & SEM & $13-15$ \\
\hline 6 & Summary of defected UiO-66 results & $16-18$ \\
\hline 7 & 1 H NMR & 19 \\
\hline 8 & Defect analysis of HCl washed UiO-66 & 20 \\
\hline 9 & UV-VIS spectra from DMNP hydrolysis & $21-22$ \\
\hline 10 & Calculation of nodes in UiO-66 & $23-25$ \\
\hline 11 & TON calculation & 26 \\
\hline 12 & Mechanism for Hydrolysis & 27 \\
\hline
\end{tabular}




\section{Modulator Screening for UiO-66}

For the defected Ui0-66 samples the modulators were added in the amounts shown below. Defected samples were named by the modulator name and equivalents added.

Table S1. Modulator screening for UiO-66

\begin{tabular}{|c|c|c|}
\hline Modulator & Equivalents & Amount (mL) \\
\hline Acetic Acid (AA) & 20 & 0.422 \\
\hline Acetic Acid & 33 & 0.696 \\
\hline Acetic Acid & 50 & 1.055 \\
\hline Acetic Acid & 100 & 2.111 \\
\hline Acetic Acid & 150 & 3.166 \\
\hline Acetic Acid & 200 & 4.221 \\
\hline Acetic Acid & 250 & 5.277 \\
\hline Acetic Acid & 300 & 6.332 \\
\hline Formic Acid (FA) & 20 & 0.278 \\
\hline Formic Acid & 33 & 0.459 \\
\hline Formic Acid & 50 & 0.696 \\
\hline Formic Acid & 100 & 1.392 \\
\hline Formic Acid & 150 & 2.089 \\
\hline Formic Acid & 200 & 2.785 \\
\hline Formic Acid & 250 & 3.481 \\
\hline Formic Acid & 300 & 4.177 \\
\hline Difluoroacetic Acid (DFA) & 10 & 0.232 \\
\hline Difluoroacetic Acid & 20 & 0.464 \\
\hline Difluoroacetic Acid & 25 & 0.581 \\
\hline Difluoroacetic Acid & 33 & 0.766 \\
\hline Difluoroacetic Acid & 50 & 1.161 \\
\hline Trifluoroacetic Acid (TFA) & 10 & 0.282 \\
\hline Trifluoroacetic Acid & 20 & 0.565 \\
\hline Trifluoroacetic Acid & 33 & 0.930 \\
\hline Trifluoroacetic Acid & 50 & 1.412 \\
\hline Trifluoroacetic Acid & 75 & 2.118 \\
\hline
\end{tabular}




\section{UiO-66 PXRD}

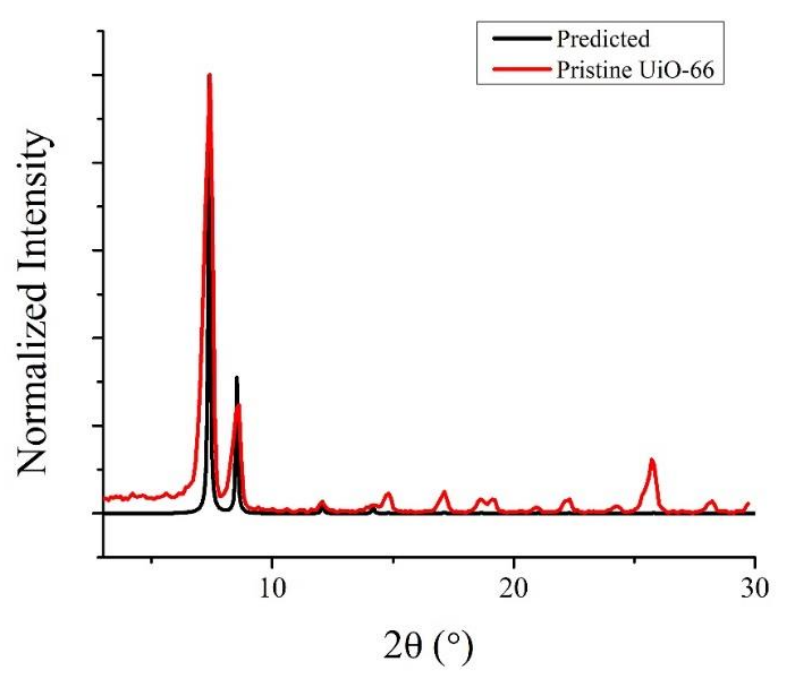

Figure S1. PXRD pattern of pristine UiO-66 (red) compared to a predicted pattern (black).
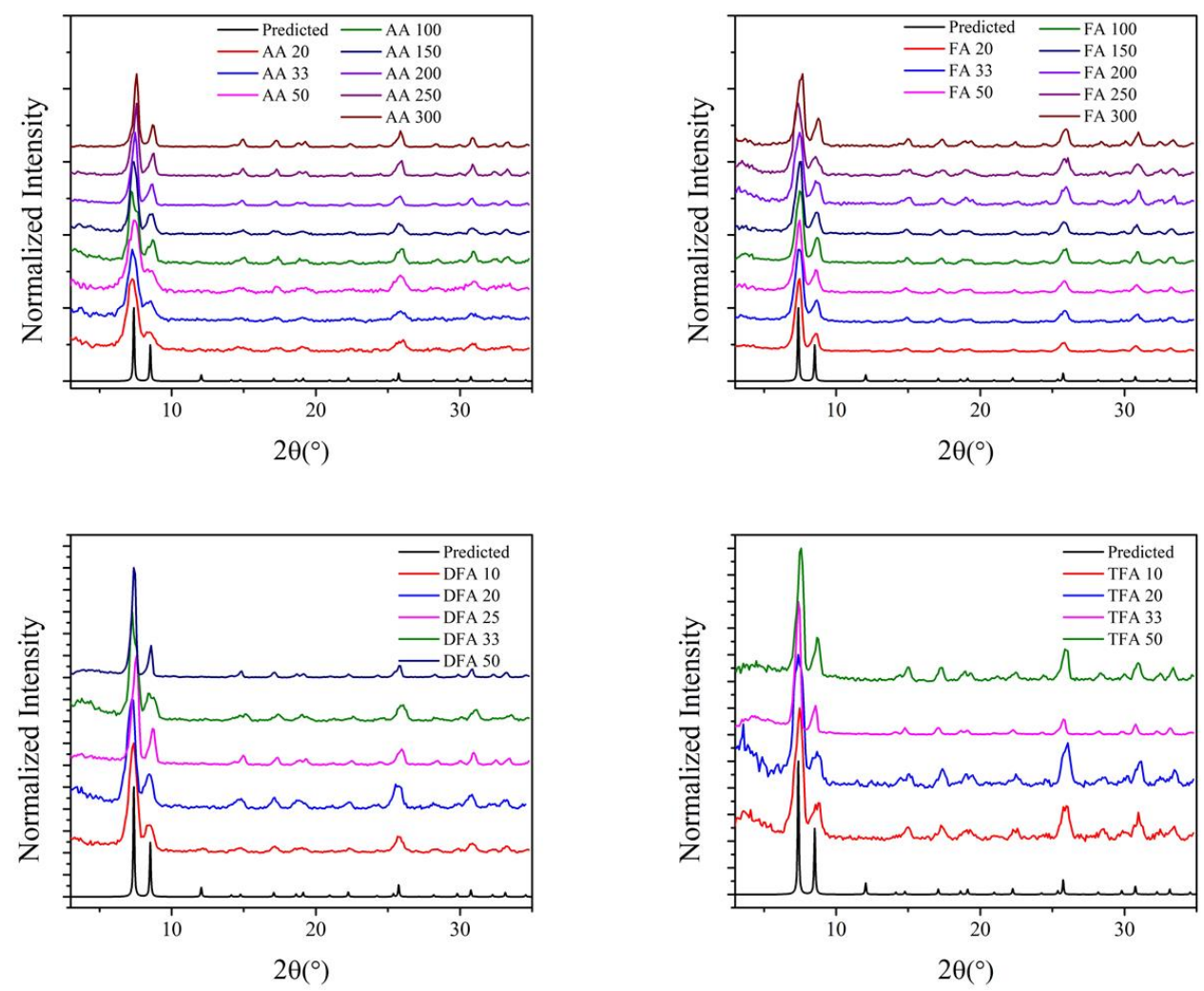

Figure S2. PXRD pattern of defected Ui0-66. Some samples (DFA 33, 50, TFA 50) show a broad peak around 3-8 $2 \theta$, indicating the presence of missing cluster defects. These samples were not included in the isolated series focused on only missing linker defects. 


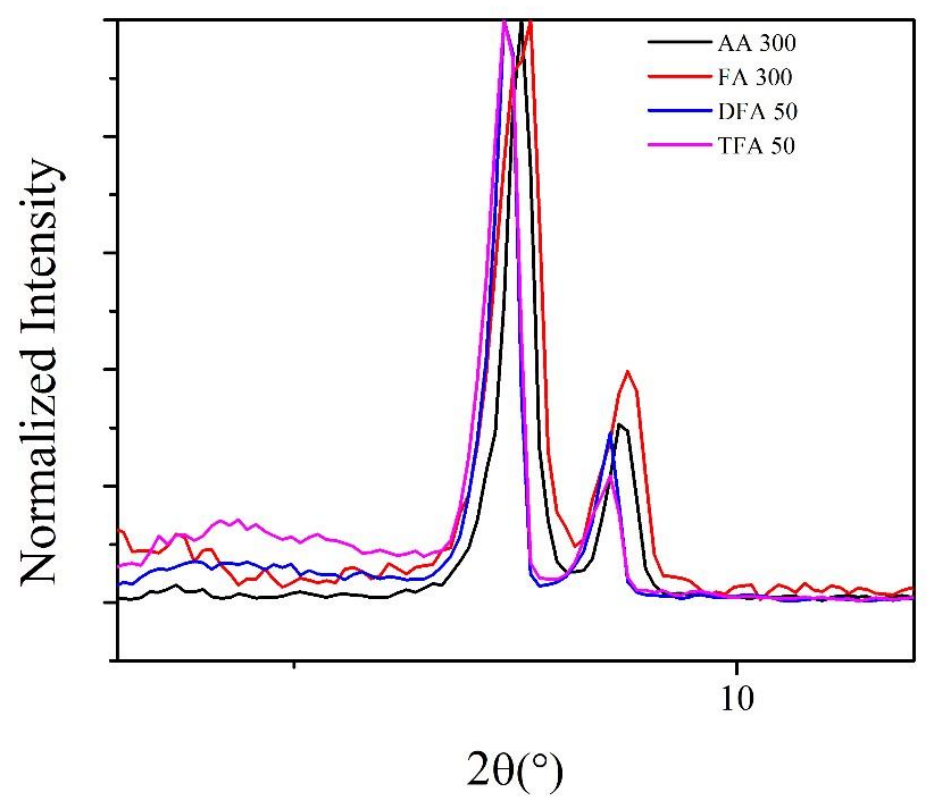

Figure S3. PXRD pattern of UiO-66 synthesized with high molar equivalents of modulator zoomed in on the low angle region. Both samples synthesized with DFA and TFA show a peak at $4^{\circ} 2 \theta$, indicative of missing cluster defects in the sample. Samples prepared with AA or FA may show a slight increase in background (red, FA), but lower intensity at $4^{\circ}$ $2 \theta$.

4 


\section{Discussion on TGA for determining defects in MOFs}

Determining defects through TGA has been well-established in other works. ${ }^{1}$ In short, the MOF is heated to temperatures above $550{ }^{\circ} \mathrm{C}$ under air until the sample completely decomposes into $\mathrm{ZrO}_{2}$. The weight loss between the final $\mathrm{ZrO}_{2}$ and the plateau directly preceding this $\left(\mathrm{W}_{\text {plat }}\right)$ can then be used to calculate a weight loss due to MOF linker. Dividing the total weight loss of organic material by the weight loss per linker, the number of linkers in the MOF can be calculated. Equation S1 shows the calculation for weight loss per linker for UiO-66. For a pristine, defect free sample the weight directly preceding organic decomposition ( $\mathrm{W}_{\text {ideal }}$ ) is $220.2 \%$, the final weight ( $\mathrm{W}_{\text {End }}$ ) is normalized to $100 \%$, and number of linkers is 6, which gives a weight loss per linker of $20.03 \%$. This value is used in equation S2 which calculates the number of missing linkers in the framework. Here, $W_{\text {plat }}$ is the experimentally observed plateau directly proceeding final decomposition, and the difference between $W_{\text {plat }}$ and $W_{\text {End }}$ give the total weight loss of the framework due to organic linkers. Finally, equation S3 gives the defect level as a percent, based on an ideal structure of UiO-66 and 6 linkers per node.

Weight per Linker $=\frac{W_{\text {ideal }}-W_{\text {End }}}{\text { Number of Linkers }}=20.03$

$$
\begin{aligned}
& \text { Defects }=6-\frac{W_{\text {plat }}-W_{\text {End }}}{20.03} \\
& \% \text { Defect }=\frac{\text { Defects }}{6} \times 100
\end{aligned}
$$

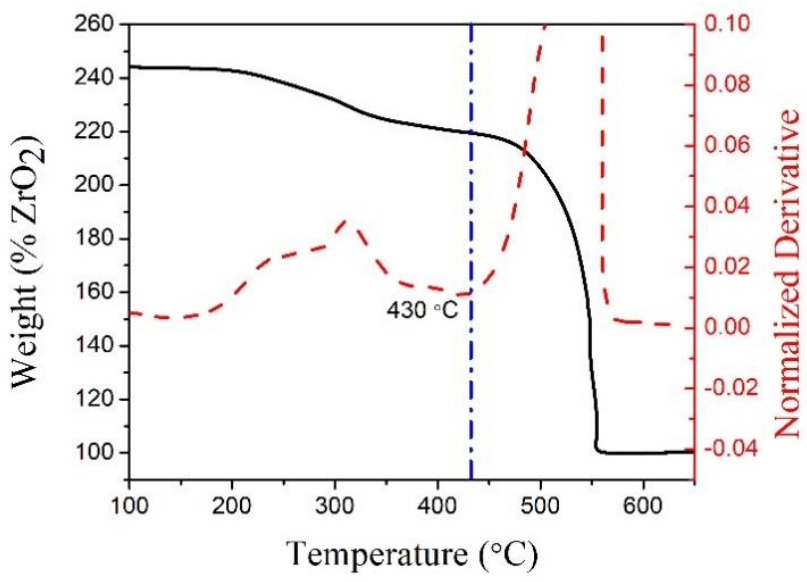

Figure S4. A sample TGA of a pristine UiO-66 sample (black trace) shown with the derivative weight loss plot (red trace). The temperature for $\mathrm{W}_{\text {plat }}$ is chosen based on a local minimum in the derivative plot, which occurs at $430{ }^{\circ} \mathrm{C}$ here $(\mathrm{blue}$ line).

The TGA plots for UiO-66 contain the same three weight loss events consistent with literature precedent at around 300 ${ }^{\circ} \mathrm{C}, 350{ }^{\circ} \mathrm{C}$ and $550{ }^{\circ} \mathrm{C}$ which correlate to DMF, dehydroxylation of the MOF node, and ligand loss, respectively. Despite the prevalence of TGA for analyzing defects in MOF literature, little discussion concerning limit of detection, the effects of gas environment, ramp rate, and final temperature have been reported previously.

To establish a limit of detection for defect analysis in UiO-66, four batches of pristine UiO-66 (denoted P-UiO-66-X, where $\mathrm{X}=$ batch number 1-4) were run under the same conditions on different instruments. The goal of this experiment was to gain insight into a real-world limit of detection, i.e. how reproducible is the defect level of a particular sample between different labs. The instruments used for defect characterization of UiO-66 were:

Instrument 1 - Discovery TGA5500

Instrument 2 - TA Instruments Q-50 thermogravimetric analyzer

Instrument 3 -TA instruments TGA-5500 
Approximately 10-15 mg of each sample was loaded onto a Pt pan, the samples were run under air at a ramp rate of 10 ${ }^{\circ} \mathrm{C} /$ minute from room temperature to $650^{\circ} \mathrm{C}$. The results of this experiment are shown in Figure S4 and summarized in Table S2.
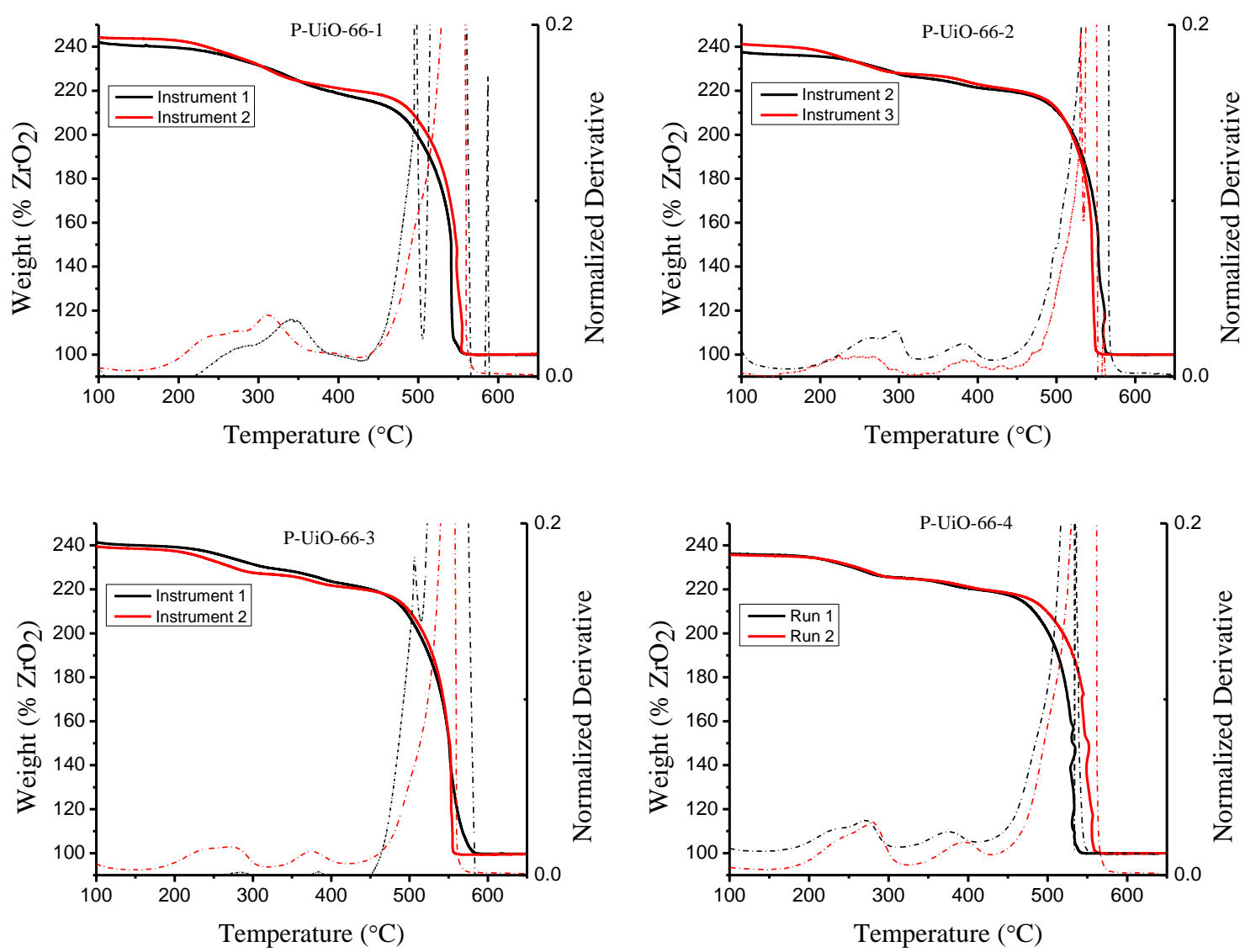

Figure S5: TGA of all pristine UiO-66 samples run across multiple instruments.

Table S2. Summary of defect level determined on different instruments.

\begin{tabular}{|l|l|l|l|}
\hline Sample & Instrument & Defect (\%) & 95\% C.I. \\
\cline { 1 - 3 } P-UiO-66-1 & Instrument 1 & 2.28 & \multirow{2}{*}{2.51} \\
\cline { 1 - 2 } P-UiO-66-1 & Instrument 2 & 0.50 & \\
\cline { 1 - 2 } P-UiO-66-2 & Instrument 2 & -0.14 & \multirow{2}{*}{1.21} \\
\cline { 1 - 2 } P-UiO-66-2 & Instrument 3 & -0.99 & \\
\cline { 1 - 3 } P-UiO-66-3 & Instrument 1 & -2.01 & \multirow{2}{*}{2.37} \\
\cline { 1 - 2 } P-UiO-66-3 & Instrument 2 & -0.33 & \\
\cline { 1 - 2 } P-UiO-66-4 & Instrument 3 & -0.05 & \multirow{2}{*}{0.49} \\
\cline { 1 - 2 } P-UiO-66-4 & Instrument 3 & -0.39 & \\
\hline
\end{tabular}


As seen in P-UiO-66-1 the same sample, run under the same conditions, may report defect levels within a range of $2.51 \%$ depending on the instrument used. Similar fluctuations are observed for the other P-UiO-66 samples, suggesting the error is not due to a single poorly calibrated instrument, but rather random error associated with TGA defect detection. This is not to suggest that a single lab cannot reproduce results within $2.51 \%$ defect level, but rather to suggest that reproducibility between groups cannot be distinguished below this point due to variations in the instruments used. For comparison, P-UiO-66-4 was analyzed twice on the same instrument, to highlight the difference in batch-to-batch variability within a single lab compared to reproducibility between labs. P-UiO-66-4 shows a high level of reproducibility, with a 95\% CI $\sim 5$ times smaller than P-UiO-66-1. On a single instrument, UiO-66 defect levels can be reported within $0.5 \%$, but when a synthetic preparation is repeated in a different lab results should be considered identical when calculated within $2.5 \%$ of reported values.

After establishing a limit of detection, other aspects of TGA defect analysis were studied. It is commonly discussed that defect analysis must occur in an oxidizing atmosphere to ensure complete degradation of the organic linker. This assumption is critical for the calculation of defects, and most TGA defect characterization is run under air or some similar N2/02 mixture. As expected, TGA plots for UiO-66 under $\mathrm{N}_{2}$ and air are significantly different (Figure S6) due to incomplete combustion of the linker under $\mathrm{N}_{2}$.

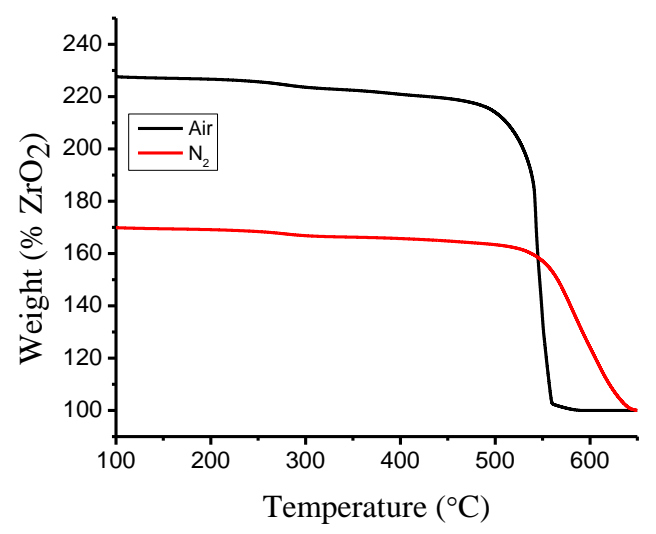

Figure S6: TGA of pristine UiO-66 under air and $\mathrm{N}_{2}$ environments.

Ramp rate for defect analysis is typically slow, again citing the need for complete combustion of the linker for the proper calculation of defect level. However, discussion of defect level at different ramp rates is surprisingly absent from the literature. Figure s7 shows the same pristine UiO-66 sample run at ramp rates of $5{ }^{\circ} \mathrm{C} / \mathrm{min}, 10^{\circ} \mathrm{C} / \mathrm{min}$ and $20^{\circ} \mathrm{C} / \mathrm{min}$. Notably, as the ramp rate increased, the onset of linker decomposition shifted to higher values, from $\sim 450{ }^{\circ} \mathrm{C}$ at $5^{\circ} \mathrm{C} / \mathrm{min}$, to $\sim 480^{\circ} \mathrm{C}$ at $10^{\circ} \mathrm{C} / \mathrm{min}$, to $\sim 500{ }^{\circ} \mathrm{C}$ at $20^{\circ} \mathrm{C} / \mathrm{min}$. Despite the large shift in decomposition temperature, the defect level between all three runs is similar (Table S3), with smaller differences than might result from simply using different instruments.

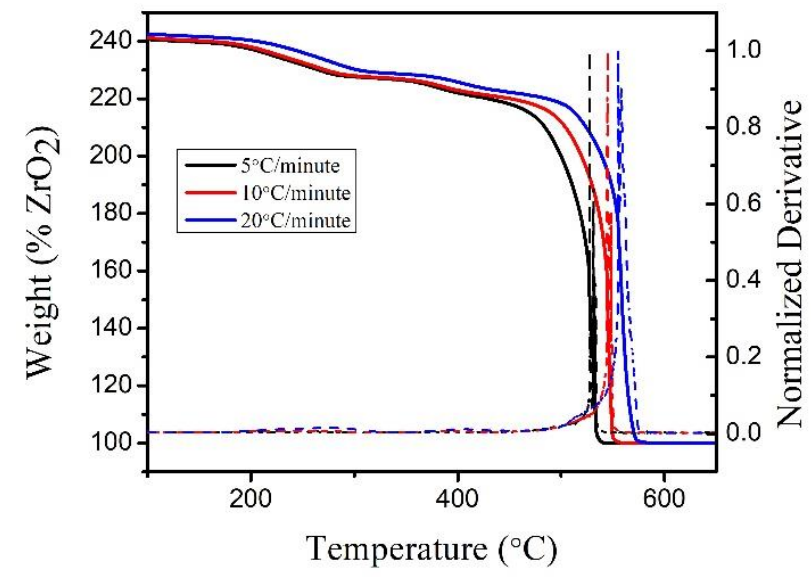

Table S3. Defect level determined at varying ramp rates.

\begin{tabular}{|l|l|}
\hline Ramp Rate & Defect Level \\
\hline $5 \mathrm{C} / \mathrm{min}$ & $0.67 \%$ \\
\hline $10 \mathrm{C} / \mathrm{min}$ & $1.13 \%$ \\
\hline $20 \mathrm{C} / \mathrm{min}$ & $1.9 \%$ \\
\hline
\end{tabular}

Figure S7. TGA of pristine UiO-66 at different ramp rates. 
While slower ramp rates are crucial for resolution between steps and identifying temperature stability of material, they are likely less important for defect analysis in MOFs for a few reasons: (1) the decomposition temperature plays no role in the calculation of missing linkers and (2) by using the method outlined above, or another method such as TGA-DSC the temperature of $W_{\text {plat }}$ is determined for each experiment, rather than for the general case of UiO-66. Any shift in the decomposition temperature between runs will result in a similar temperature shift for $\mathrm{W}_{\text {plat }}$.

Finally, different temperature end points have been observed in defect analysis of Zr-based MOFs. While the temperatures chosen are well past the decomposition point of the framework, there is some question as to what temperature is necessary such that only $\mathrm{ZrO}_{2}$ remains. The same pristine UiO-66 sample was analyzed to $650{ }^{\circ} \mathrm{C}$ and $900^{\circ} \mathrm{C}$ with the defect level reported in Table S4. Similar to the observation above, the final defect level changes only slightly based on the final temperature chosen. It is interesting to note the small peak in the weight percent going from $650^{\circ} \mathrm{C}$ to $900^{\circ} \mathrm{C}$. This could be due to the motion of the analysis pan, but it could also indicate chemistry is occurring at $\mathrm{ZrO}_{2}$ under high temperatures. For this reason, we propose a final end point of $650{ }^{\circ} \mathrm{C}$, where decomposition is complete and further reactions are unlikely to occur

Table S4. Defect level based on final temperature.

\begin{tabular}{|l|l|}
\hline Final Temperature & Defect Level \\
\hline $650{ }^{\circ} \mathrm{C}$ & $-0.81 \%$ \\
\hline $900{ }^{\circ} \mathrm{C}$ & $-2.44 \%$ \\
\hline
\end{tabular}




\section{TGA of defected UiO-66}
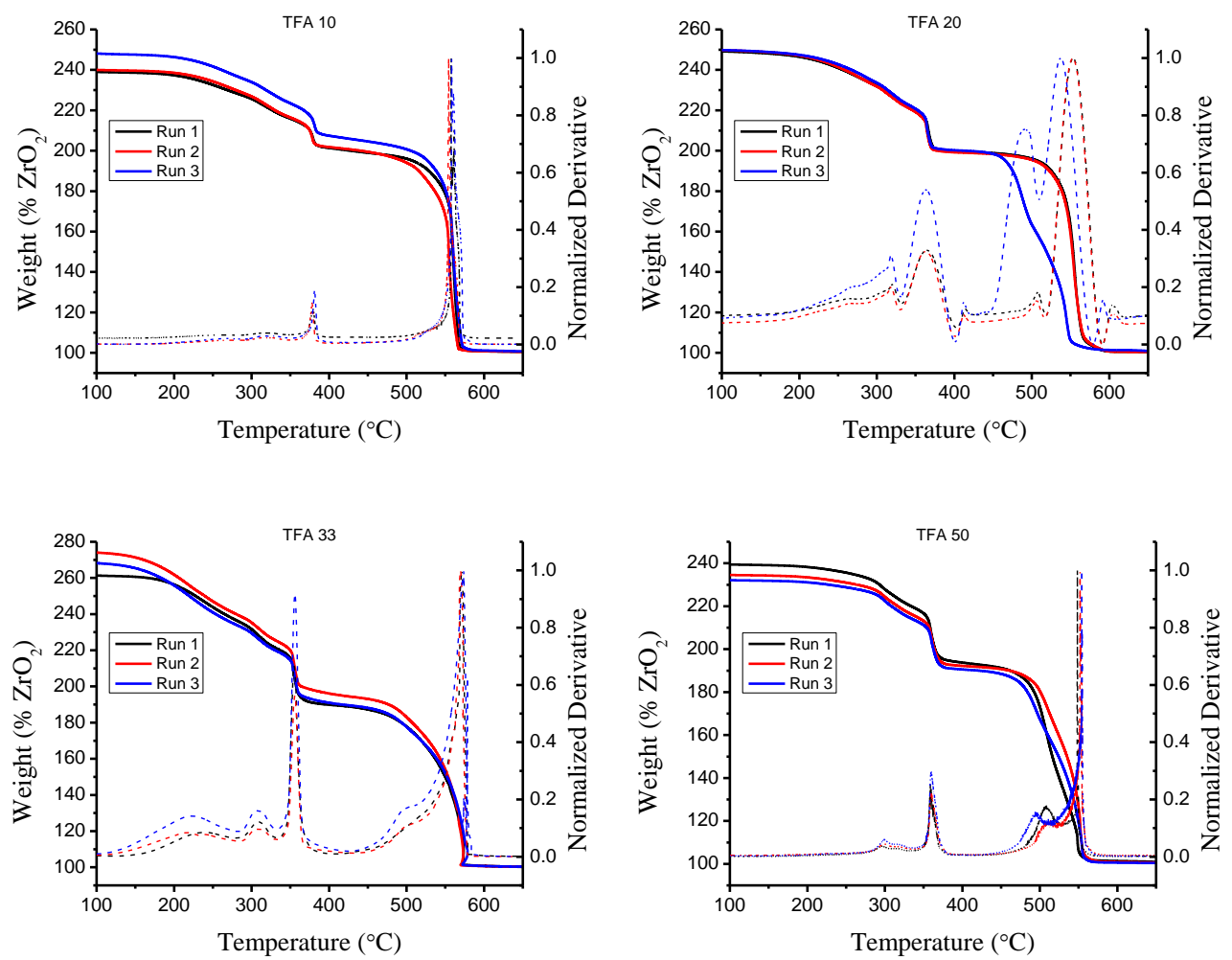

Figure S8. TGA traces for defected UiO-66 samples synthesized with trifluoroacetic acid (solid) with their derivative traces (dashed). 

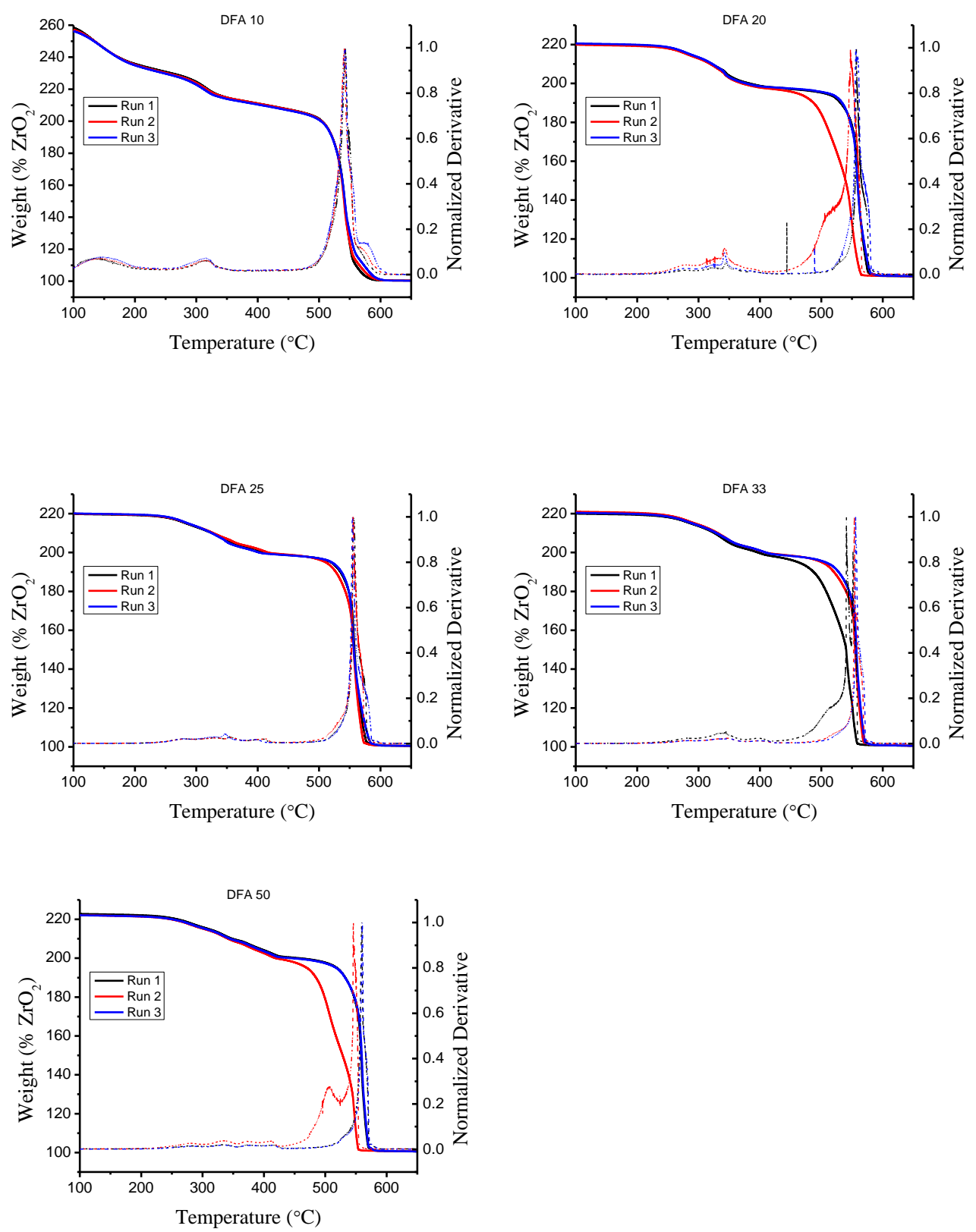

Figure S9. TGA traces for defected Ui0-66 samples synthesized with difluoroacetic acid (solid) with their derivative traces (dashed). 

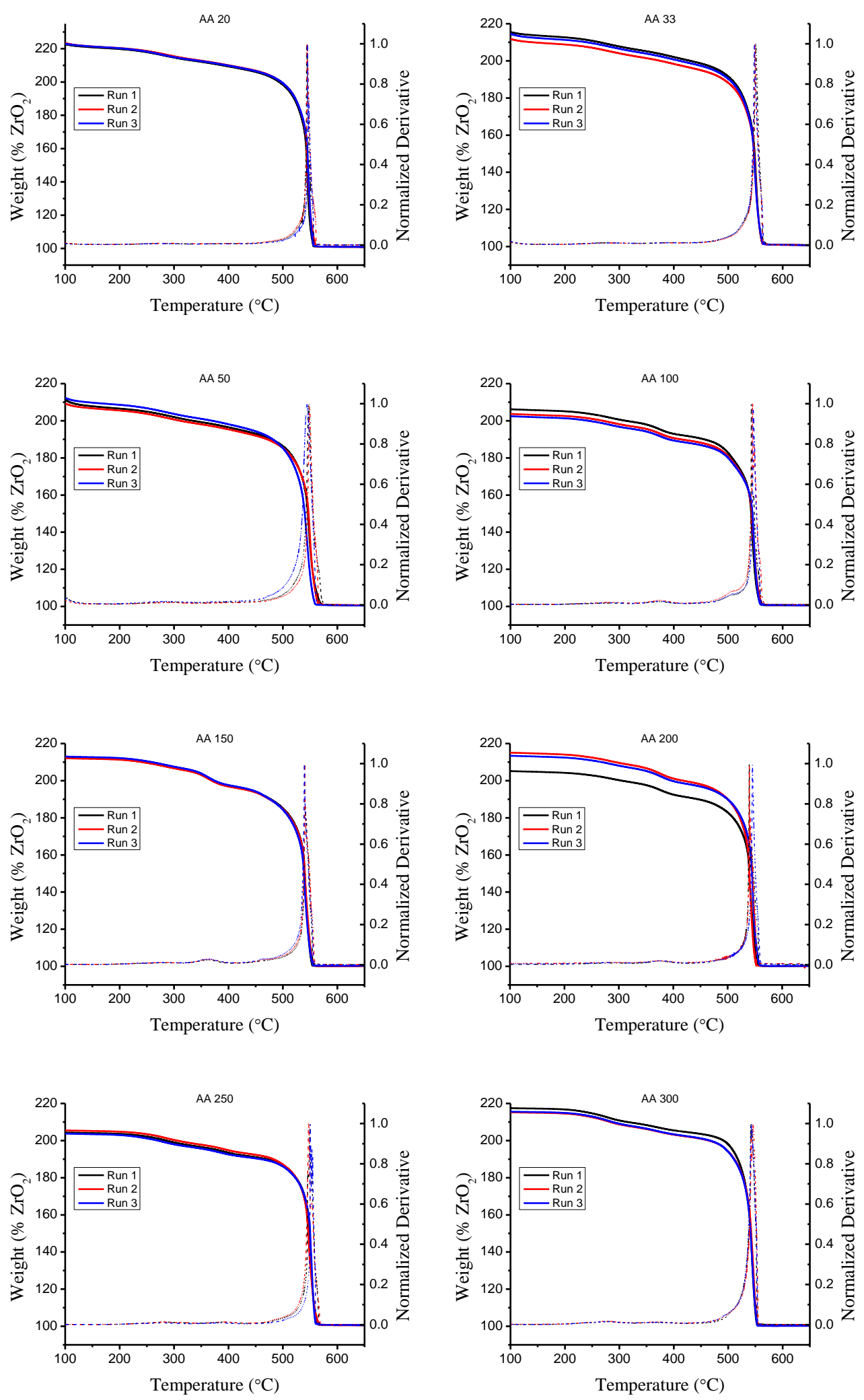

Figure S10. TGA traces for defected UiO-66 samples synthesized with acetic acid (solid) with their derivative traces (dashed). 

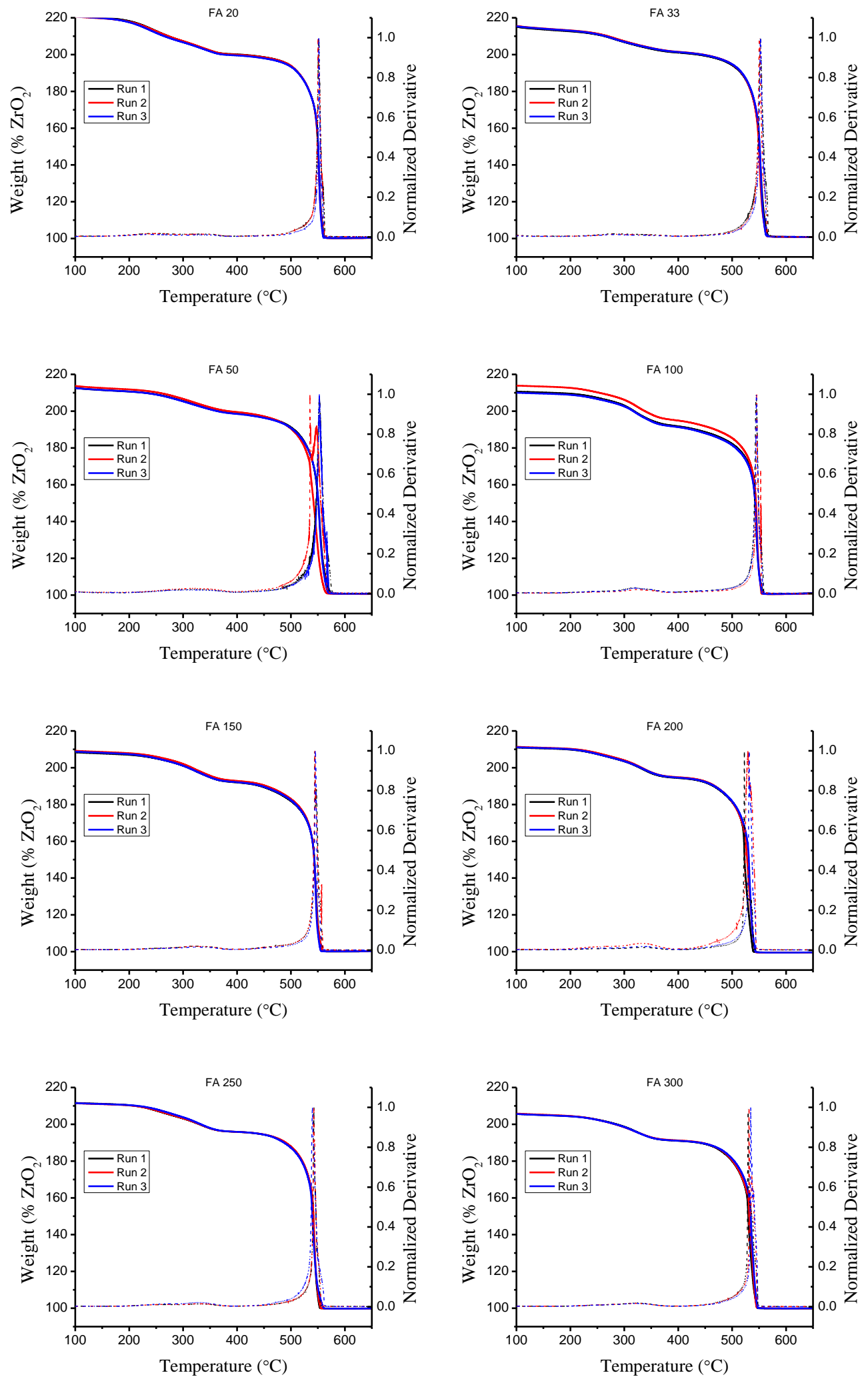

Figure S11. TGA traces for defected Ui0-66 samples synthesized with formic acid (solid) with their derivative traces (dashed). 


\section{UiO-66 SEM}

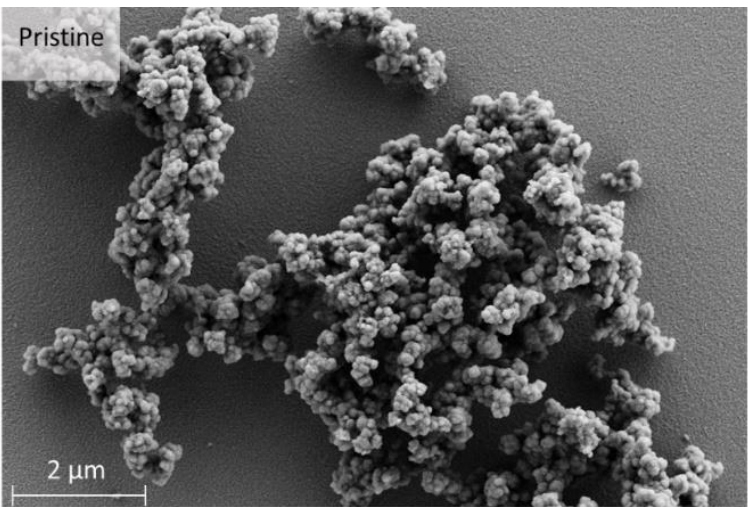

Figure S12. SEM of pristine Ui0-66. Particles averaged $440 \mathrm{~nm}$ in size with spherical morphology. Particles tended to aggregate together, despite sonication of the sample prior to SEM analysis.
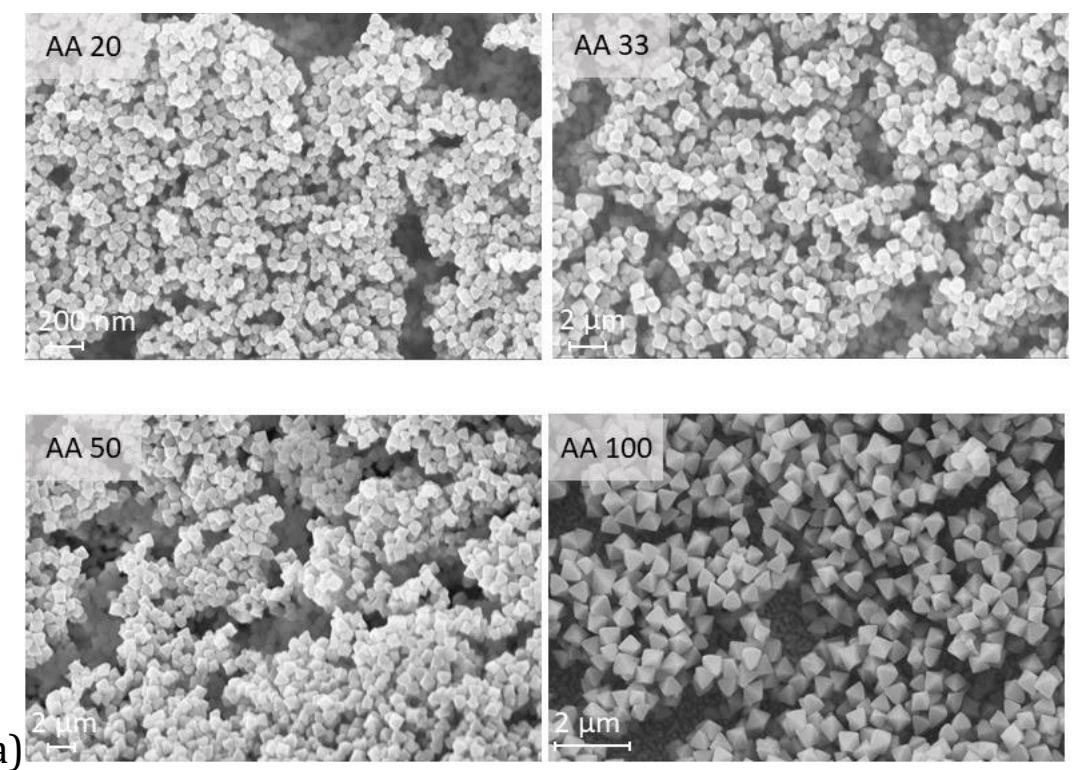


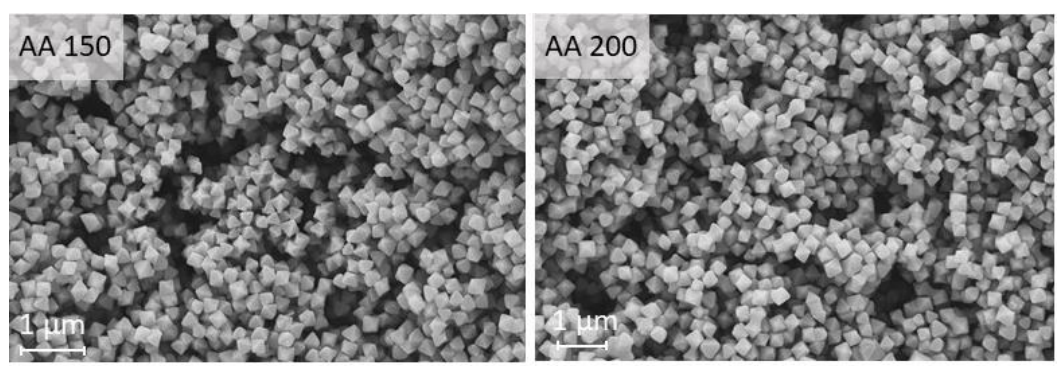

b)
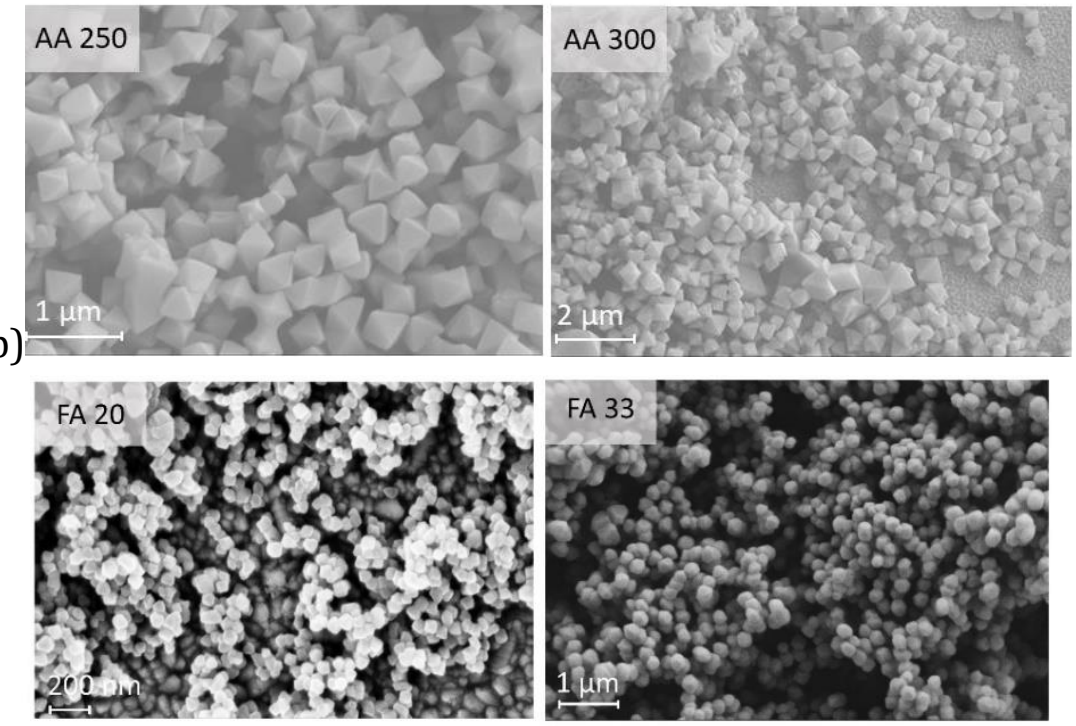

c)
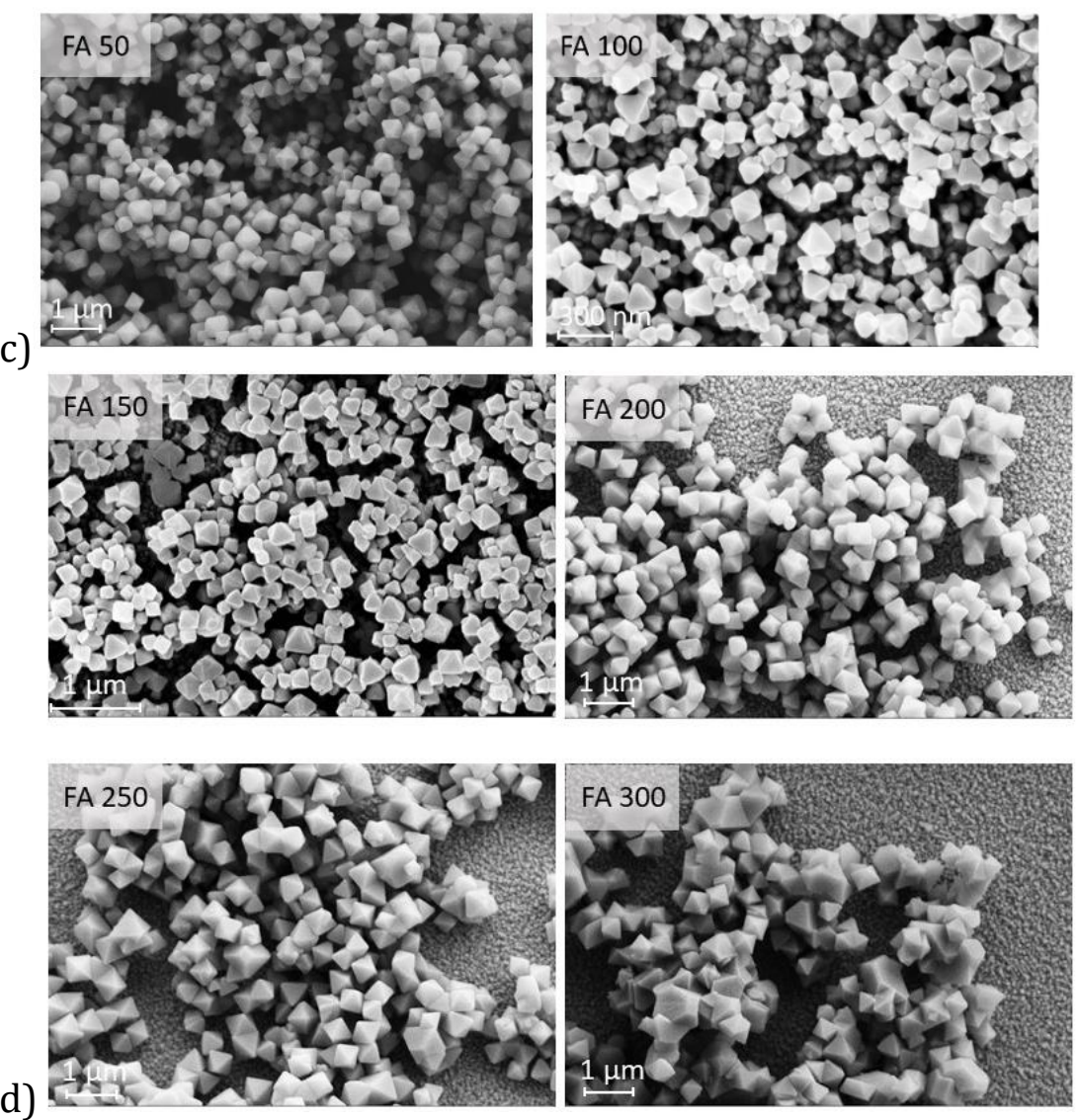

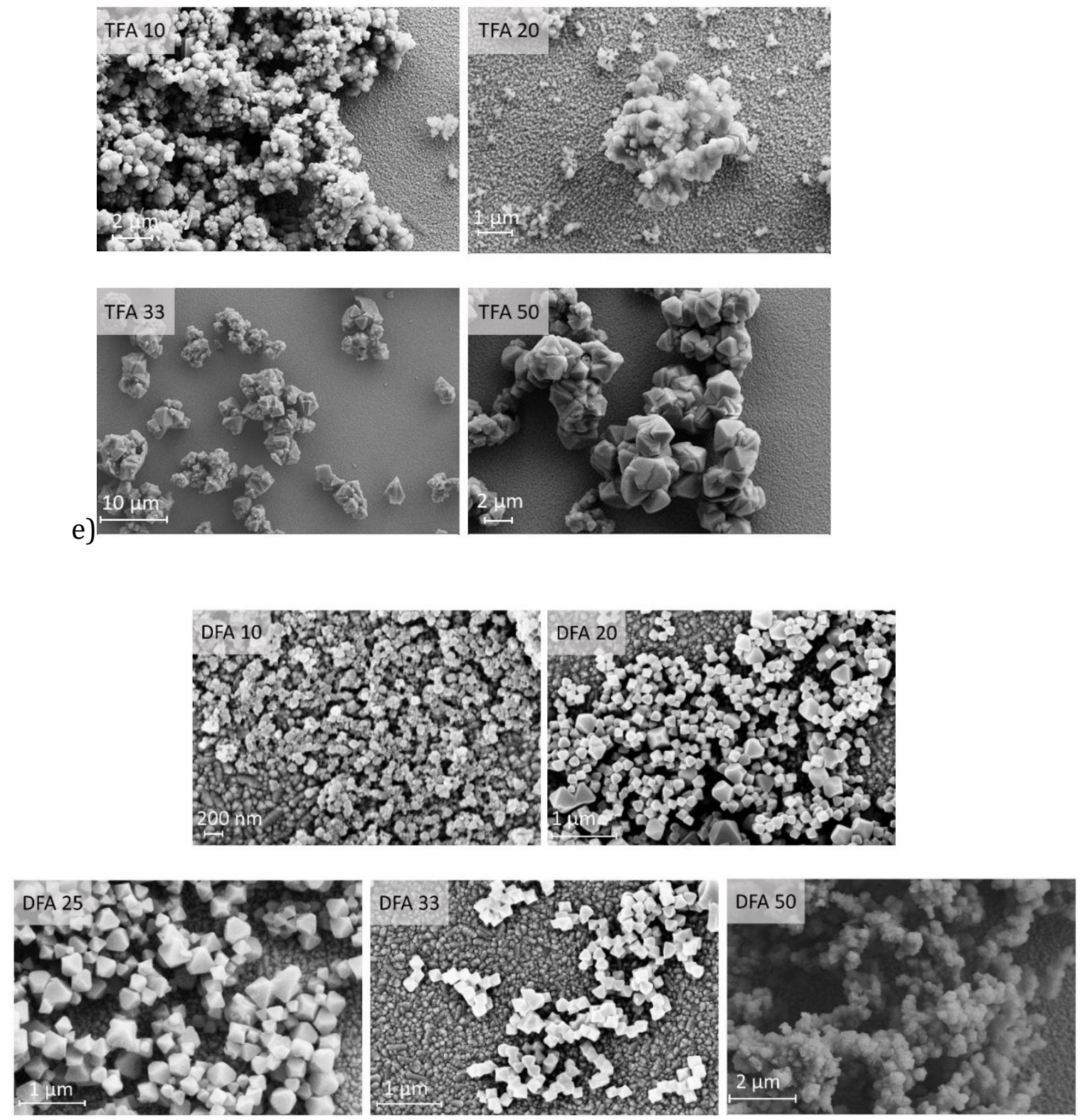

f)

Figure S13. SEM of defected UiO-66. 4a-b) Acetic acid series, 4c-d) Formic acid series, 4e) TFA series, 4f) DFA series. 


\section{Summary of Defected UiO-66 results}

Table S5. Particle size and defect level of defected UiO-66 samples.

\begin{tabular}{|c|c|c|}
\hline Sample & Defect Level (\%) & Particle Size (nm) \\
\hline AA 20 & $9 \pm 2$ & $81 \pm 17$ \\
\hline AA 33 & $11 \pm 1$ & $104 \pm 15$ \\
\hline AA 50 & $12 \pm 1$ & $129 \pm 25$ \\
\hline AA 100 & $19 \pm 1$ & $345 \pm 88$ \\
\hline AA 150 & $16.1 \pm 0.5$ & $343 \pm 57$ \\
\hline AA 200 & $14.3 \pm 0.5$ & $402 \pm 96$ \\
\hline AA 250 & $16 \pm 2$ & $465 \pm 74$ \\
\hline AA 300 & $14 \pm 1$ & $595 \pm 117$ \\
\hline FA 20 & $16.9 \pm 0.3$ & $77 \pm 12$ \\
\hline FA 33 & $15.7 \pm 0.2$ & $278 \pm 34$ \\
\hline FA 50 & $17.7 \pm 0.5$ & $301 \pm 94$ \\
\hline FA 100 & $22 \pm 2$ & $137 \pm 35$ \\
\hline FA 150 & $23.2 \pm 0.4$ & $261 \pm 64$ \\
\hline FA 200 & $21.3 \pm 0.2$ & $577 \pm 75$ \\
\hline FA 250 & $20.21 \pm 0.01$ & $664 \pm 79$ \\
\hline FA 300 & $24.2 \pm 0.1$ & $635 \pm 114$ \\
\hline DFA 10 & $10.8 \pm 0.3$ & $99 \pm 11$ \\
\hline DFA 20 & $18.8 \pm 0.1$ & $242 \pm 89$ \\
\hline DFA 25 & $17.8 \pm 0.2$ & $360 \pm 106$ \\
\hline DFA 33 & $17.9 \pm 0.4$ & $300 \pm 132$ \\
\hline DFA 50 & $16.6 \pm 0.5$ & $322 \pm 50$. \\
\hline TFA 10 & $14 \pm 2$ & $345 \pm 92$ \\
\hline TFA 20 & $17.2 \pm 0.4$ & $266 \pm 41$ \\
\hline TFA 33 & $20 . \pm 2$ & $1877 \pm 600$. \\
\hline TFA 50 & $23 \pm 1$ & $1908 \pm 612$ \\
\hline & & \\
\hline
\end{tabular}




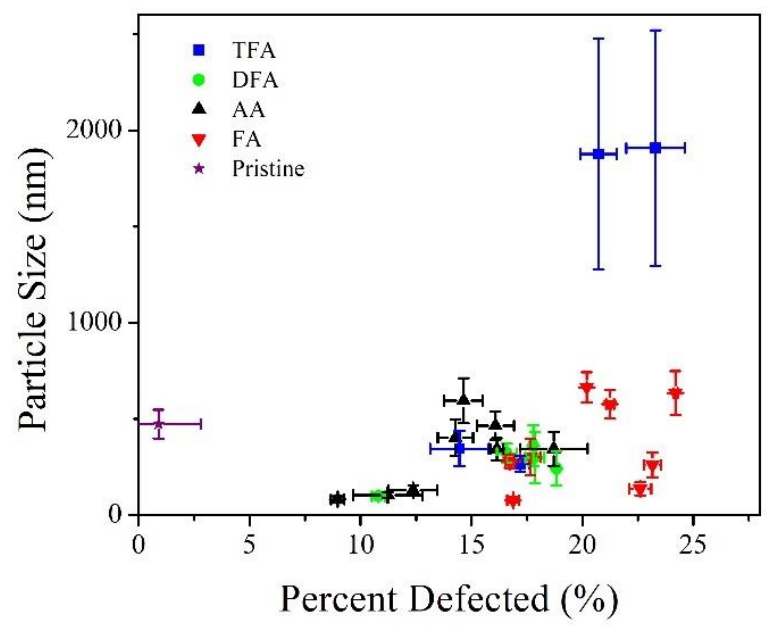

Figure S14. Full UiO-66 screening study results.

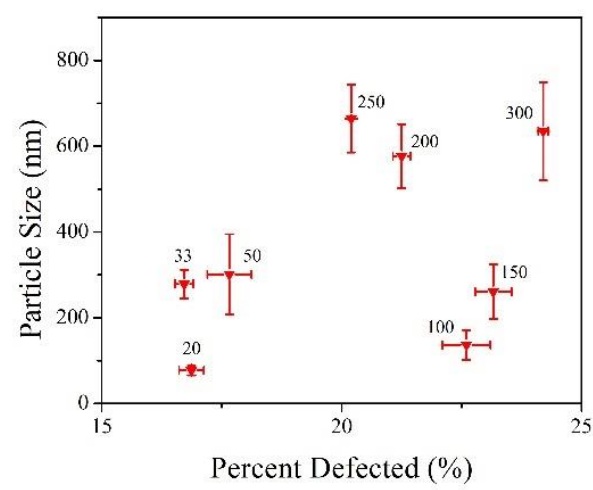

Figure S15. Screening study results for UiO-66 prepared with formic acid as the modulator, with the molar equivalents of formic acid shown above each point.

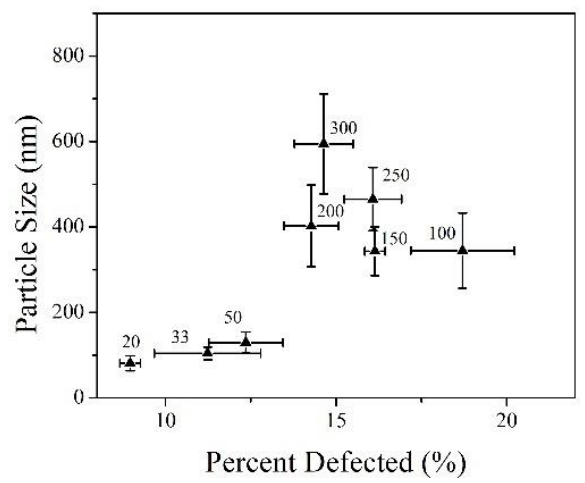

Figure S16. Screening study results for UiO-66 prepared with acetic acid as the modulator, with the molar equivalents of acetic acid shown above each point. 


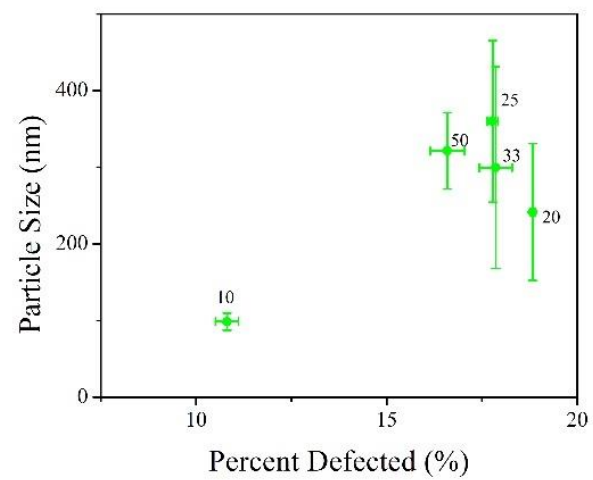

Figure S17. Screening study results for Ui0-66 prepared with difluoroacetic acid as the modulator, with the molar equivalents of difluoroacetic acid shown above each point.

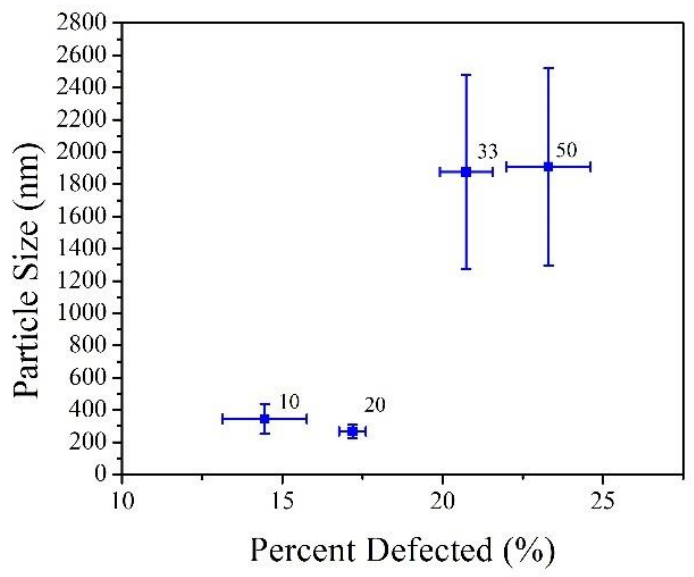

Figure S18. Screening study results for Ui0-66 prepared with trifluoracetic acid as the modulator, with the molar equivalents of trifluoroacetic acid shown above each point. 


\section{7. ${ }^{1} \mathrm{H}$ NMR}

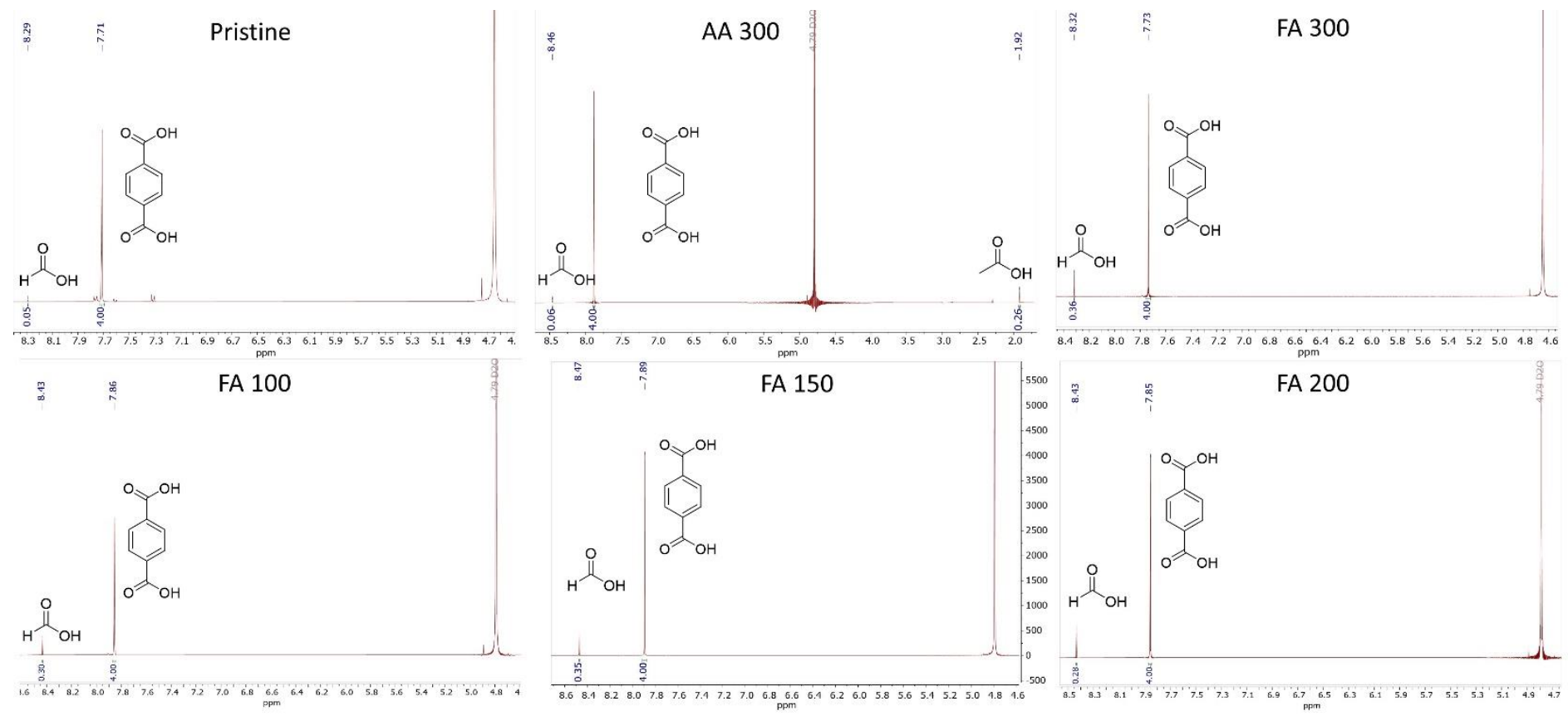

Figure S19. ${ }^{1} \mathrm{H}$ NMR of digested UiO-66 samples prepared in basic $\mathrm{D}_{2} \mathrm{O}$. 


\section{Defect analysis of $\mathrm{HCl}$ washed UiO-66}

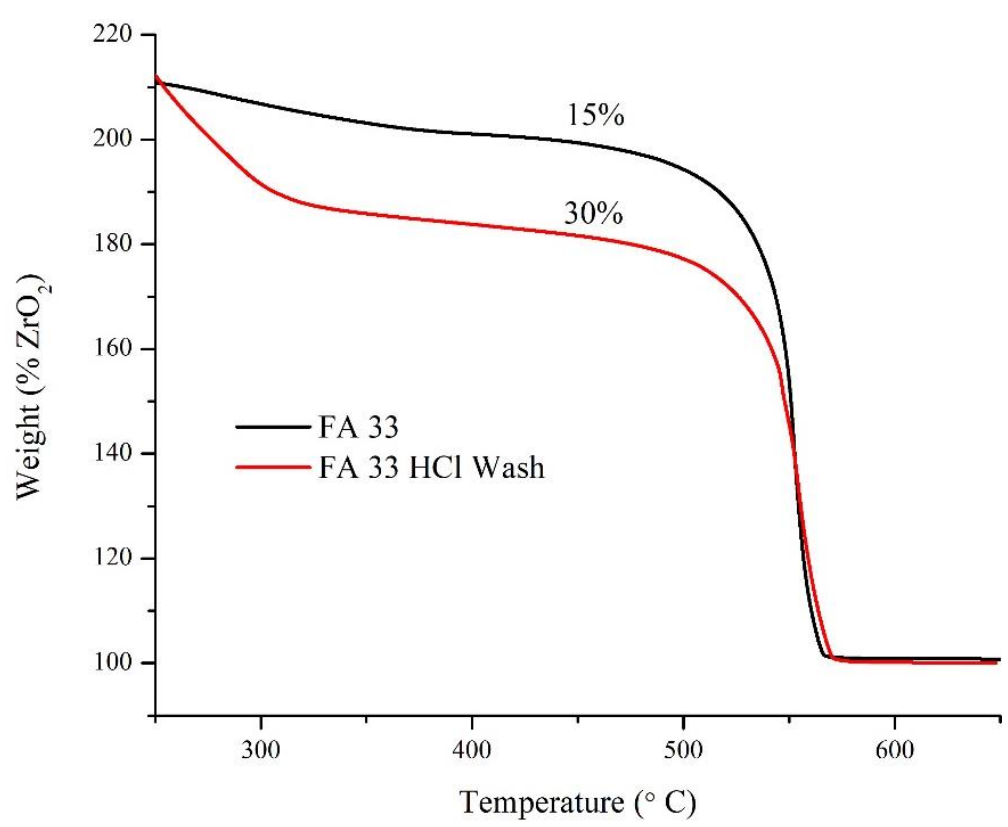

Figure S20. Thermogravimetric analysis for defected Ui0-66 pre and post $\mathrm{HCl}$ wash. Following the washing procedure outlined for NU-1000 results in a significant increase in defect level in UiO-66, and therefore was not used in this study. ${ }^{2}$ 


\section{UV-VIS spectra from DMNP hydrolysis}

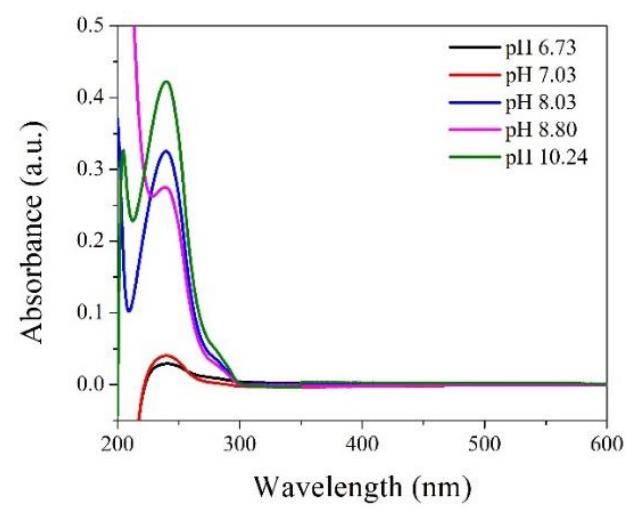

Figure S21. UV-VIS spectra of UiO-66 in aqueous ethylmorpholine solution at various $\mathrm{pH}$ (adjusted with addition of acetic acid). Growth of a peak at $\lambda_{\max }=240 \mathrm{~nm}$ is due to terephthalic acid caused from the degradation of UiO-66 at high $\mathrm{pH}$. At $\mathrm{pH}=7$, the absorbace at $240 \mathrm{~nm}$ is minimal, suggesting greater stability at this $\mathrm{pH}$, which was used for all future experiments.

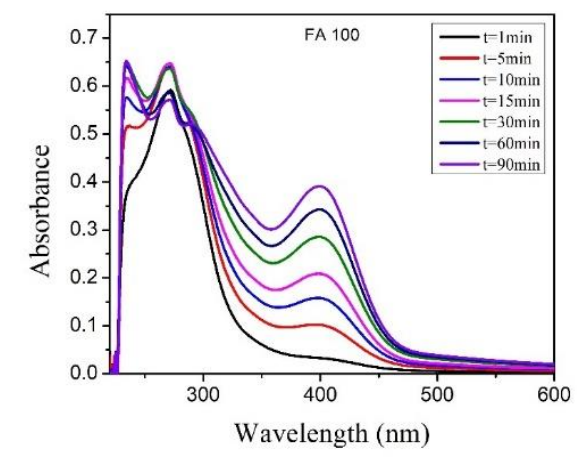

Figure S22. UV-VIS spectrum measuring DMNP hydrolysis over the course of 90 minutes for FA 100.

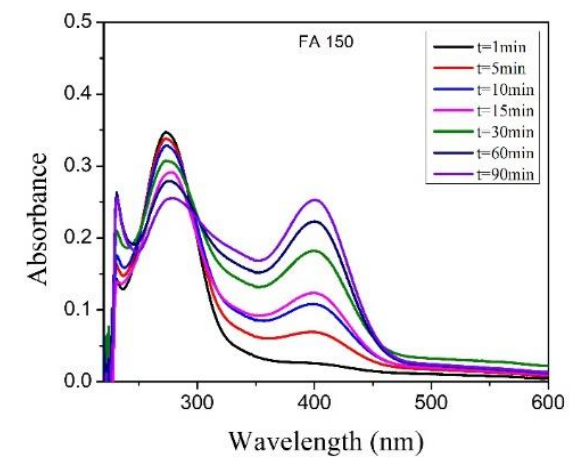

Figure S23. UV-VIS spectrum measuring DMNP hydrolysis over the course of 90 minutes for FA 150. 


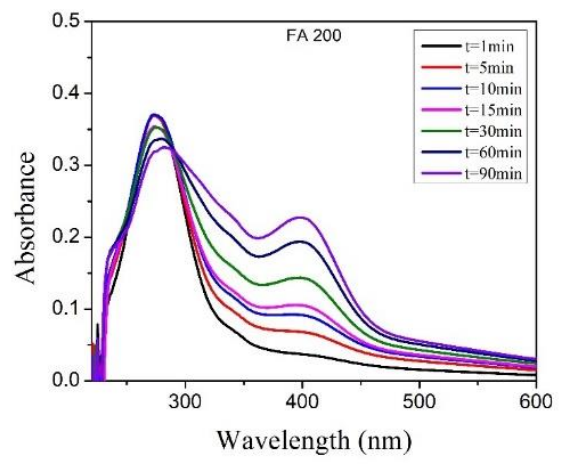

Figure S24. UV-VIS spectrum measuring DMNP hydrolysis over the course of 90 minutes for FA 200.

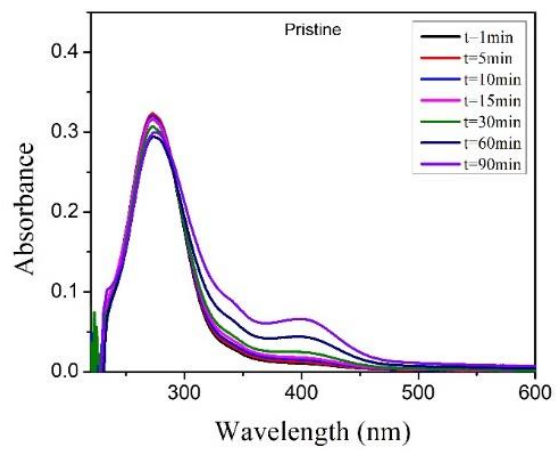

Figure S25. UV-VIS spectrum measuring DMNP hydrolysis over the course of 90 minutes for Pristine UiO-66.

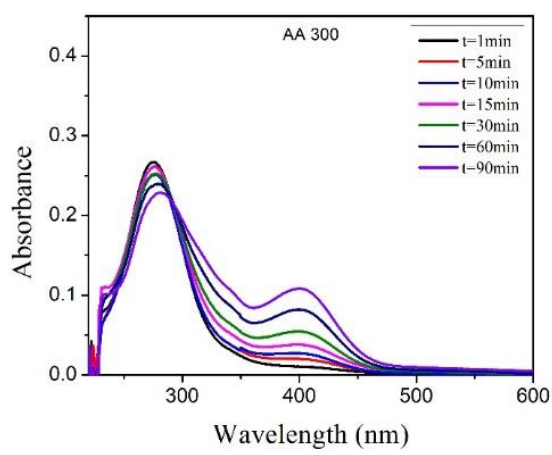

Figure S26. UV-VIS spectrum measuring DMNP hydrolysis over the course of 90 minutes for AA 300.

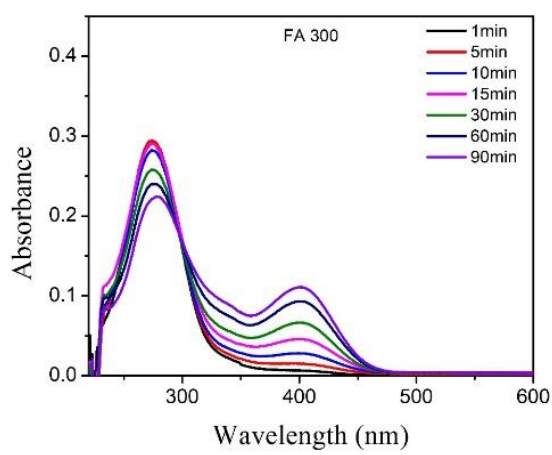

Figure S27. UV-VIS spectrum measuring DMNP hydrolysis over the course of 90 minutes for FA 300. 


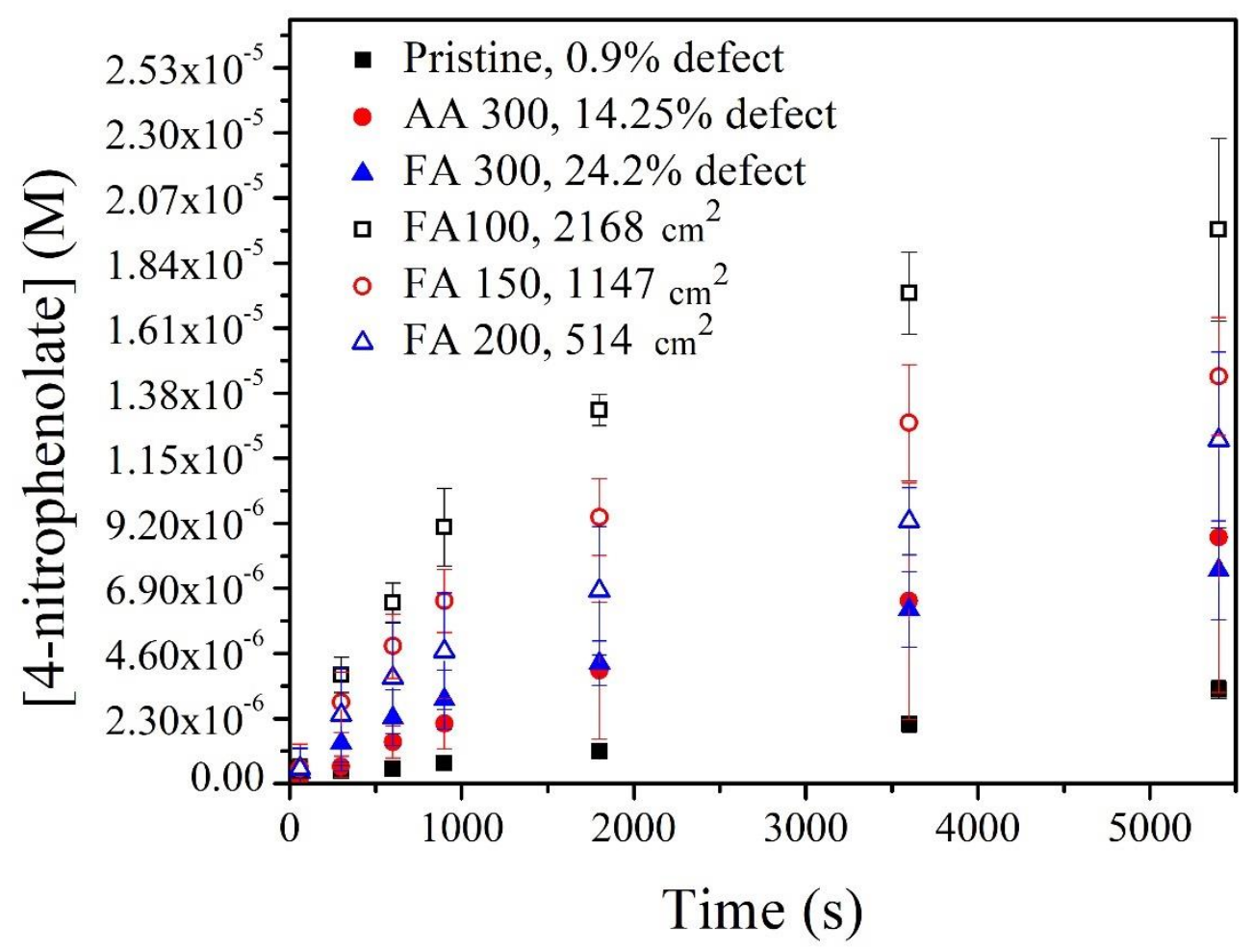

Figure S28. Concentration of 4-nitrophenolate over 90 minutes for UiO-66 with changing defect level (solid) and changing particle size (open). 


\section{Calculation of Surface Nodes in Ui0-66}

To calculate the number of nodes on the surface of UiO-66 we considered a perfectly octahedral particle where the length of the particle tip-to-tip is the same as the width of the particle. To determine the number of nodes on the surface of a particle, we wanted to calculate the number of nodes at each edge, on each face and at the tips.

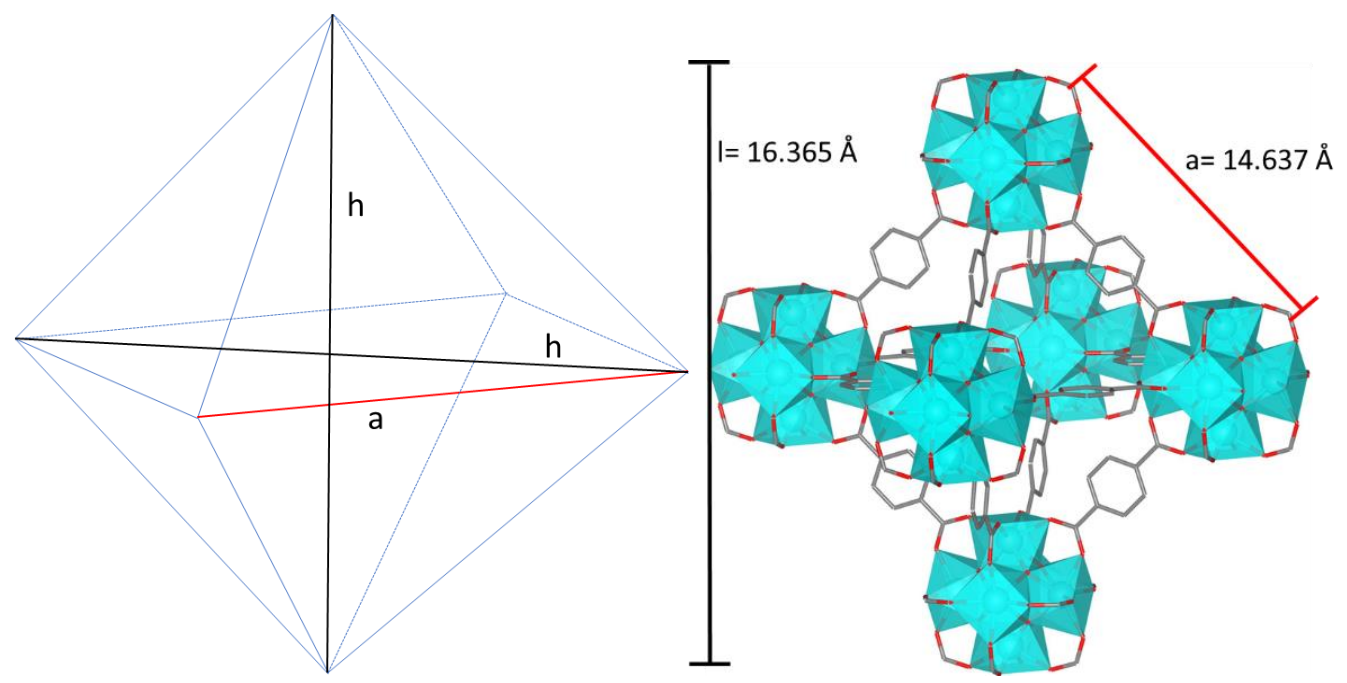

Edge Nodes:

The edge length of an octahedral particle can be calculated given the height of the particle from equation S4 below:

$$
\text { (S4) } \quad a=\sqrt{\frac{l^{2}}{2}}
$$

Where l is the particle length. Given the node-to-node distance of $14.637 \AA$ An UiO-66 the number of edge nodes in UiO-66 can be found from equation S5:

$$
\text { Edge nodes }=\frac{a}{14.637} \times 12
$$

Face Nodes:

The face of an octahedral particle of UiO-66 is an equilateral triangle with side length a (as calculated above). Therefore, the area of that triangle can be found from equation S6:

$$
A_{\text {face }}=\frac{\sqrt{3}}{4} a^{2}
$$

Similarly, the same area on a single UiO-66 octahedron can be calculated from the same equation, where a is the node-node distance of $14.637 \AA$.

The number of single octahedron faces that can fit into one face of a UiO-66 particle can be found from equation S7:

$$
\text { Units per Face }=\frac{A_{\text {face }}}{A_{\text {single octahedron }}}
$$


Given that each node on the face of a particle will be shared between 6 "small triangles", the number of nodes in each octahedron face is $3 / 6$ or 0.5 nodes/unit. So the number of nodes on a the faces of a particle can be found from equation S8:

$$
\text { Face nodes }=[8 \times(\text { Units per face } * 0.5)]-(\text { edge nodes }+ \text { nodes at the point })
$$

Where there are 6 nodes at the point of an octahedron.

The total number of nodes at the surface can be found by the addition of face nodes, edge nodes and point nodes in equation S9:

$$
\text { (S9) Surface nodes }=\text { edge nodes }+ \text { face nodes }+ \text { point nodes }
$$

To compare the number of face nodes to the total nodes in a particle of UiO-66, we calculated the volume of an octahedral particle (eq. S10):

$$
\text { (S10) } \quad V_{\text {particle }}=2 \times a^{2} \frac{l}{6}
$$

The same calculation can be done for the volume of a single octahedron considering the $\mathrm{l}$ of a single octahedron to be $16.365 \AA$, and a to be the node-node distance.

The number of single octahedrons that will fit into a particle can be calculated from equation S11:

$$
\text { (S11) Number of units }=\frac{V_{\text {particle }}}{V_{\text {single octahedron }}}
$$

To calculate the number of nodes in a particle, we considered each node to be shared by 4 other small octahedrons, therefore the number of nodes per small octahedron is $6 * 1 / 4$ or 1.5 . The number of nodes in a particle of UiO-66 then is given by equation S12:

\section{(S12) Total nodes $=1.5 \times$ Number of units}

And the percentage of surface nodes can be found by taking the ratio of surface nodes to total nodes. An example calculation for FA100 is given below.

Example: Nodes in FA 100 (particle size $136 \mathrm{~nm}$ )

\section{Edge Nodes:}

$a=\sqrt{\frac{1360 \AA^{2}}{2}}=961.67 \AA$

Edge nodes $=\frac{961.67}{14.637} \times 12=788$ nodes

Face Nodes:

$$
\begin{aligned}
& A_{\text {face }}=\frac{\sqrt{3}}{4} 961.67^{2}=400450.147 \AA^{2} \\
& A_{\text {small face }}=\frac{\sqrt{3}}{4} 14.637^{2}=92.769 \AA^{2} \\
& \text { Units per Face }=\frac{400450.147 \AA^{2}}{92.769 \AA^{2}}=4316 \\
& \text { Face nodes }=[8 \times(4316 * 0.5)]-(788+6)=16470 \text { nodes }
\end{aligned}
$$

Nodes at the surface $=17264$ nodes

Interior nodes: 
$V_{\text {particle }}=2 \times 961.67 \AA^{2} \frac{1360 \AA}{6}=4.19 \times 10^{8} \AA^{3}$

$V_{\text {single octahedral }}=2 \times 14.637 \AA^{2} \frac{16.3647 \AA}{6}=1168.66 \AA^{3}$

Number of units $=\frac{4.19 \times 10^{8} \AA^{3}}{1168.66 \AA^{3}}=3.59 \times 10^{5}$

Total nodes $=1.5 \times 3.59 \times 10^{5}=5.38 \times 10^{5}$

$\%$ nodes at the surface: $3.2 \%$

\begin{tabular}{|c|c|}
\hline Sample & \% nodes at surface (\%) \\
\hline Pristine & 0.93 \\
\hline AA 300 & 0.74 \\
\hline FA 300 & 0.69 \\
\hline FA 100 & 3.2 \\
\hline FA 150 & 1.69 \\
\hline FA 200 & 0.76 \\
\hline
\end{tabular}




\section{Determination of TON in UiO-66}

Initially, the TON of the reaction was calculated using the moles of UiO-66 added to the reaction. The formulas and molecular weights for each sample are given below:

Pristine UiO-66: $\mathrm{Zr}_{6} \mathrm{O}_{4}(\mathrm{OH})_{4}(\mathrm{BDC})_{6} 1664.16 \mathrm{~g} / \mathrm{mol}$

AA300: $\mathrm{Zr}_{6} \mathrm{O}_{4}(\mathrm{OH})_{4}(\mathrm{BDC})_{5.14}$ (Acetate) 0.51 (Formate) $0.341568 .39 \mathrm{~g} / \mathrm{mol}$

FA300: $\mathrm{Zr}_{6} \mathrm{O}_{4}(\mathrm{OH})_{4}(\mathrm{BDC})_{4.54}$ (Formate) $1.451493 .83 \mathrm{~g} / \mathrm{mol}$

FA100: $\mathrm{Zr}_{6} \mathrm{O}_{4}(\mathrm{OH})_{4}(\mathrm{BDC})_{4.64}$ (Formate) ${ }_{1.36} 1502.14 \mathrm{~g} / \mathrm{mol}$

FA150: $\mathrm{Zr}_{6} \mathrm{O}_{4}(\mathrm{OH})_{4}(\mathrm{BDC})_{4.61}$ (Formate) ${ }_{1.39} 1498.57 \mathrm{~g} / \mathrm{mol}$

FA200: $\mathrm{Zr}_{6} \mathrm{O}_{4}(\mathrm{OH})_{4}(\mathrm{BDC})_{4.54}$ (Formate) $1.451493 .83 \mathrm{~g} / \mathrm{mol}$

To adjust for only the surface nodes, the moles of UiO-66 was converted to moles of $\mathrm{Zr}$ nodes, considering $6 \mathrm{Zr}$ nodes for each mole of MOF. The moles of $\mathrm{Zr}$ nodes was then multiplied by the $\%$ surface nodes to determine the TON adjusted for active sites.

For the particle size series, since the nodes are expected to be identical (same modulator/defect level in all three samples), it is reasonable to expect that the TON should be consistent when the correct number of active catalysts are determined. Since the TON is higher for FA 150 and FA 200, it is likely that the surface node calculation is underestimating the number of catalytically active sites. To probe this, we wanted to determine the number of active sites needed for FA 150 and FA 200 if the TON was the same as FA 100 (eq. S13).

$$
\text { (S13) mol active catalyst }=\frac{[4-N P]}{20.34}
$$

A new percentage of active nodes was calculated from the moles of active catalyst and the moles of node added for each sample (eq. S14).

(S14) Percent Active Nodes $=\frac{\text { mol active catalyst }}{\text { mol MOF nodes added }} \times 100$

This percentage can be used with the total number of MOF nodes to calculate the number of active nodes in the sample (eq. S15).

(S15) Number Active Nodes $=$ Total Nodes $\times \frac{\text { Percent Active Nodes }}{100}$

Since we already determined the number of surface nodes for each sample, the number of interior nodes that are active for each sample is calculated by subtracting the number of surface nodes from the number of active nodes. The number of interior nodes was divided by the calculated number of nodes in the second layer (nodes/face*8 faces) and expressed as a percentage of nodes in the $2^{\text {nd }}$ layer that would need to be active if only a penetration to the second node layer $(\sim 1.5 \mathrm{~nm})$ is achieved.

\begin{tabular}{|l|l|l|}
\hline Sample & $\begin{array}{l}\text { Interior Nodes Needed to normalize } \\
\text { TON to FA } 100\end{array}$ & $\begin{array}{l}\text { Percentage of active nodes in } \\
\text { the 2 }\end{array}$ \\
\hline FA 150 layer
\end{tabular}

It should be noted that the number of interior nodes that are active for catalysis are quite small $(0.7 \%$ of all nodes for FA 150, 0.4\% FA 200). This is not to suggest any definitive penetration depth for either sample, only to highlight the relatively small number of interior nodes participating in catalysis. 


\section{Mechanism of Hydrolysis}

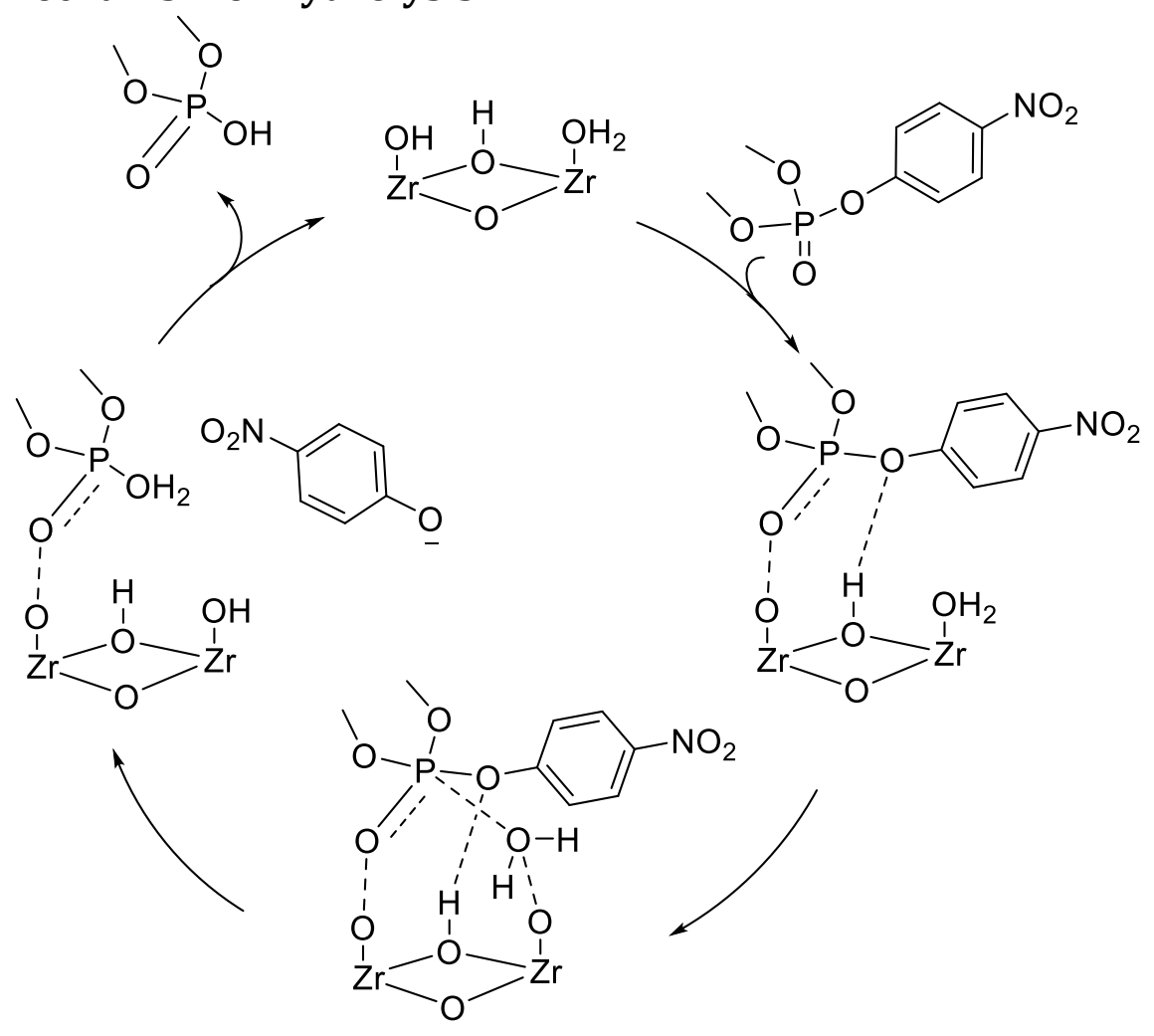

Figure S29. Proposed mechanism for hydrolysis of DMNP at the nodes of UiO-66.

\section{References:}

(1) Shearer, G. C.; Chavan, S.; Bordiga, S.; Svelle, S.; Olsbye, U.; Lillerud, K. P. Defect Engineering: Tuning the Porosity and Composition of the Metal-Organic Framework UiO-66 via Modulated Synthesis. Chem. Mater. 2016, 28 (11), 3749-3761.

(2) Lu, Z.; Liu, J.; Zhang, X.; Liao, Y.; Wang, R.; Zhang, K.; Lyu, J.; Farha, O. K.; Hupp, J. T. Node-Accessible Zirconium MOFs. J. Am. Chem. Soc. 2020, 142 (50), 21110-21121. 